\title{
Temporal sequence effects in auditory oddity discrimination'
}

The oddity method was used in assessing pitch, loudness, simultaneous tone, successive tone, and speech sound discrimination in 35 normal children and 15 children with learning problems. With this method three auditory stimuli are presented, two of which are identical, and the $S$ is required to indicate the temporal position of the odd stimulus. For both groups, discrimination was most accurate when the odd stimulus was in the third position. These results could be explained by assuming that the oddity response was based upon successive SameDifferent judgments of the first and second stimuli and the second and third stimuli, since a correct response to third-position oddity would require only a Same judgment of the first and second stimuli. Other findings were not as easily explained by this simple model, and alternative hypotheses are discussed.

Visual oddity learning has been studied in humans (e.g., Gollin \& Shirk, 1966; Lipsett \& Serunian, 1963; Strong, 1966) and animals (Bitterman \& Wodinsky, 1953; Boyd \& Warren, 1957; Moon \& Harlow, 1955; Strong \& Hedges, 1966). In the standard visual oddity problem the $S$ is presented with a horizontal array of three stimuli, two of which are identical, and is rewarded for response to the odd stimulus. The position of the odd stimulus is changed from trial to trial. The $\mathrm{S}$ must learn to respond to a relation, difference between the odd and the identical stimuli, rather than to any absolute properties of the stimuli (House, 1964a).

The majority of investigations of the visual oddity problem have been concerned with the amount and type of training required for solution of the oddity problem. It has been found that oddity learning varies as a function of species (Strong \& Hedges, 1966), chronological age (Gollin \& Shirk, 1966; Hill, 1965; Strong, 1966), mental age (Ellis \& Sloan, 1959), number of identical stimuli (Gollin, Saravo, \& Saltin, 1967), presence of irrelevant stimulus dimensions (Lubker \& Spiker, 1966), and similarity between odd and identical stimuli (Lipsett \& LoLordo, 1963); and oddity learning has been compared with other types of discrimination learning (Bitterman \& Wodinsky, 1953; Hill, 1965; House, 1964b; Scott, 1964). Human Ss of sufficient chronological and mental age can learn the oddity response almost immediately when given verbal instructions or special pretraining. Then the oddity method may be used to assess the S's ability to differentiate among stimuli or to train him to make the required discriminations (e.g., Candland \& Conklyn, 1962; House, 1964b).

Although the oddity method has been used in studies of auditory discrimination (e.g., Pickett \& Mártony, 1968), there has been no explicit analysis of auditory oddity responding per se. A major difference between auditory oddity and the standard visual oddity problem is that auditory stimuli must be presented in a temporal sequence. As a consequence, the $S$ does not have the opportunity for repeated scanning of simultaneous stimuli. Choice of the odd stimulus requires reception, storage, and comparison of three or more successively-presented sounds. Because of these relatively complex task requirements, accuracy of responding may vary as a function of the temporal position of the odd stimulus.
In the present study, a series of five auditory oddity tests were given to children with learning problems and children with normal learning ability. Differences between groups in overall accuracy for these tests and for standard audiometric tests have been discussed in a separate paper. 4 The present report is concerned with a more detailed analysis of oddity responses to determine whether performance of the auditory oddity task is affected by the temporal position of the odd stimulus.

\section{METHOD}

Subjects were 35 children with normal school achievement and 15 children with learning problems. The normal group included five children at each age level from 6 through 12, and the learning problem group included 2 children at age 8,10 at age 9 , and 3 at age 10. Pure-tone thresholds of all Ss, at 1000 and $2000 \mathrm{~Hz}$, were well within normal limits as determined by standard audiometric procedures.

Each S was given five oddity tests in the following order: pitch, loudness, simultaneous tone, speech sound, and successive tone. The tests were tape recorded and presented binaurally through earphones with a Uher Universal 5,000 tape recorder. All except the loudness test were presented at a comfortable listening level of about $40 \mathrm{~dB}$ relative to the normal threshold (ISO) for a $2000-\mathrm{Hz}$ tone.

The response device had six back-lighted windows, $1 \times 3 / 4$ in., mounted in two rows of three. The numbers 1,2 , and 3 were printed on the upper windows, and the lower windows served as response keys. On each trial the $S$ heard three successive sounds, two of which were the same. He pushed the window under the numbered window corresponding to the sound that he judged to be odd. A correct judgment lighted the window pushed and the numbered window above it. An incorrect response lighted only the window containing the number of the odd stimulus.

The position of the odd stimulus was randomized, with the restriction that each position was odd within every set of three trials. This restriction insured an adequate sample of responses to each position when testing was terminated according to an error criterion. Although randomization within three-trial blocks could facilitate a guessing strategy, previous experience had indicated that children do not adopt such strategies in this type of situation.

To make certain that each $S$ understood the task, an initial practice series of 10 simple verbal sequences such as "same, same, different" and "high, low, high" was given. On all tests except the speech sound test, the odd sound became increasingly similar to the other sounds over trials, and testing was discontinued after six errors in nine trials.

The pitch and loudness tests were recorded from an audio oscillator with associated electronic switch and interval timer. The stimuli were $1 \mathrm{sec}$ in duration with a rise-decay time of $25 \mathrm{msec}$ and an interstimulus interval of $1 \mathrm{sec}$. Pure tones of 1950 to $2050 \mathrm{~Hz}$ were presented for the pitch test, with the frequency difference of the odd tone decreased from $50 \mathrm{~Hz}$ on the first trial to $2 \mathrm{~Hz}$ on the 36th trial. For the loudness test, $2,000 \mathrm{~Hz}$ test tones were presented at an intensity of 32 to $48 \mathrm{~dB}$, with the intensity difference of the odd tone decreasing from $8 \mathrm{~dB}$ on the first trial to $0.1 \mathrm{~dB}$ on the 44 th trial. 
Table 1

Percentages of Correct Oddity Response for 35 Normal Children, with five Children at each Age Level from 6 to 12.

\begin{tabular}{|c|c|c|c|c|c|c|c|}
\hline \multirow[t]{2}{*}{ Age } & \multicolumn{3}{|c|}{ Odd Stimulus } & \multirow[t]{2}{*}{ Age } & \multicolumn{3}{|c|}{ Odd Stimulus } \\
\hline & 1 & 2 & 3 & & 1 & 2 & 3 \\
\hline Pitch & & & & Spee & and & & \\
\hline $\begin{array}{r}6 \\
7 \\
8 \\
9 \\
10 \\
11 \\
12\end{array}$ & $\begin{array}{l}37 \\
44 \\
40 \\
49 \\
33 \\
49 \\
34\end{array}$ & $\begin{array}{l}44 \\
52 \\
40 \\
35 \\
43 \\
68 \\
63\end{array}$ & $\begin{array}{l}57 \\
61 \\
58 \\
68 \\
55 \\
57 \\
69\end{array}$ & $\begin{array}{r}6 \\
7 \\
8 \\
9 \\
10 \\
11 \\
12\end{array}$ & $\begin{array}{l}84 \\
83 \\
89 \\
97 \\
86 \\
94 \\
96\end{array}$ & $\begin{array}{l}90 \\
93 \\
94 \\
99 \\
96 \\
97 \\
97\end{array}$ & $\begin{array}{l}94 \\
97 \\
99 \\
99 \\
99 \\
99 \\
99\end{array}$ \\
\hline $\begin{array}{l}\text { Loudness } \\
6 \\
7 \\
8 \\
9 \\
10 \\
11 \\
12\end{array}$ & $\begin{array}{l}30 \\
41 \\
30 \\
51 \\
41 \\
65 \\
34\end{array}$ & $\begin{array}{l}67 \\
68 \\
53 \\
58 \\
63 \\
64 \\
81\end{array}$ & $\begin{array}{l}57 \\
67 \\
89 \\
67 \\
58 \\
62 \\
76\end{array}$ & $\begin{array}{l}\text { Succ } \\
6 \\
7 \\
8 \\
9 \\
10 \\
11 \\
12\end{array}$ & $\begin{array}{r}\text { tone } \\
42 \\
31 \\
49 \\
65 \\
57 \\
70 \\
60\end{array}$ & $\begin{array}{l}39 \\
53 \\
53 \\
48 \\
63 \\
60 \\
52\end{array}$ & $\begin{array}{l}76 \\
84 \\
91 \\
93 \\
81 \\
92 \\
82\end{array}$ \\
\hline $\begin{array}{l}\text { Simultanec } \\
6 \\
7 \\
8 \\
9 \\
10 \\
11 \\
12\end{array}$ & $\begin{array}{l}\text { s to } \\
45 \\
50 \\
54 \\
58 \\
53 \\
75 \\
64\end{array}$ & $\begin{array}{l}33 \\
67 \\
66 \\
62 \\
85 \\
75 \\
69\end{array}$ & $\begin{array}{l}93 \\
83 \\
94 \\
85 \\
93 \\
92 \\
95\end{array}$ & & & & \\
\hline
\end{tabular}

Stimuli for the simultaneous tone test were two to five notes played together on a baby grand piano, with the odd stimulus varying from a difference of three semitones in one note of a two-note stimulus on the first trial to a difference of one semitone in a middle note of a five-note stimulus on the 36 th trial.

Vowel consonant combinations taken from a sound discrimination test for 6- to 8-year-old children (Templin, 1957) were used for the speech sound test, with the odd stimulus differing by one consonant sound. All Ss were given all 42 trials. Tonal sequences from the Seashore Tonal Memory Test (Seashore, Lewis, \& Saetveit, 1960) were used for the successive tone test, with one tone of the odd stimulus differing in pitch. The length of the sequences varied from three notes on the first trial to five notes on the 30th trial.

Subjects were tested individually, with the five tests given in two sessions on two different days. The children with learning problems were tested in a relatively quiet room, whereas the ambient noise level was considerably higher in the room available for testing the normal children.

\section{Normal Children}

\section{RESULTS}

The percentages of correct response for each position of the odd stimulus are shown for the five groups of normal children in Table 1. Responses tended to be most accurate when the third stimulus was odd and least accurate when the first stimulus was odd. There was a less consistent tendency for accuracy to increase with age. Separate analyses of variance were calculated for each test, as shown in Table 2. The effects of oddity position were highly significant for all tests. Age groups differed significantly only on the speech sound test, and the interactions of age and oddity position did not approach significance.

The percentages of response to each oddity position are shown in Table 3 for combined age groups. Correct responses are those in which the response coincides with the oddity position, i.e., Response 3 when the third stimulus was odd. On all tests, accuracy was lowest when the first stimulus was odd and highest when the third stimulus was odd. However, the relative amount of change varied from test to test. The significant difference in oddity position was almost entirely attributable to the large increase of accuracy from the first to the second oddity position on the loudness test, and to a large increase from the second to the third oddity position on the successive tone test. Equal increments of accuracy occurred on the pitch test, and there was roughly twice as much increase of accuracy from the first to the second as from the second to the third odd stimulus on the simultaneous tone and speech sound tests.

Table 3 also shows the percentages of incorrect response for each oddity position. When the first stimulus was odd there was a tendency to make more incorrect responses to the second than to the third stimulus. There was no consistent pattern of errors when the second or the third stimulus was odd.

\section{Children with Learning Problems}

Differences in accuracy of response to each oddity position were assessed by analysis of variance for the 15 children with learning problems, as shown in Table 4. Position effects were highly significant for all except the loudness test. Percentages of response to each odd stimulus are shown in Table 5, where it can be seen that the significant position effects were largely attributable to much greater accuracy on all tests when the third stimulus was odd. Differences in correct responses to the first and second odd stimuli were relatively small for all except the simultaneous tone test, where the lowest percentage of correct response was made to the second stimulus. There was a consistent tendency for more incorrect responses to be made to the third than to the second position when the first stimulus was odd, and also for more incorrect responses to the third than to the first position when the second stimulus was odd, suggesting a response bias for the third position. When the third stimulus was

Table 2

Summaries of Analyses of Variance of Correct Responses to the Three Odd Stimuli for Five Normal Children at each Age Level from 6 to 12 .

\begin{tabular}{|c|c|c|c|}
\hline Source & $\mathrm{df}$ & MS & $\mathbf{F}$ \\
\hline $\begin{array}{l}\text { Pitch } \\
\text { Age (A) } \\
\text { Subjects within ages (S) } \\
\text { Oddity position (O) } \\
\text { A x O } \\
\text { S } \times \text { O }\end{array}$ & $\begin{array}{r}6 \\
28 \\
2 \\
12 \\
56\end{array}$ & $\begin{array}{r}429.67 \\
726.86 \\
3485.50 \\
361.08 \\
555.20\end{array}$ & $6.28 * *$ \\
\hline $\begin{array}{l}\text { Loudness } \\
\text { Age (A) } \\
\text { Subjects within ages (S) } \\
\text { Oddity position (O) } \\
\text { A } \times \text { O } \\
\text { S } \times O\end{array}$ & $\begin{array}{r}6 \\
28 \\
2 \\
12 \\
56\end{array}$ & $\begin{array}{r}305.83 \\
384.25 \\
7195.20 \\
751.66 \\
425.00\end{array}$ & $\begin{array}{c}16.93^{* *} * \\
1.77\end{array}$ \\
\hline $\begin{array}{l}\text { Simultaneous tone } \\
\text { Age (A) } \\
\text { Subjects within ages (S) } \\
\text { Oddity position }(\mathrm{O}) \\
\text { A x O } \\
\text { S x O }\end{array}$ & $\begin{array}{r}6 \\
28 \\
2 \\
12 \\
56\end{array}$ & $\begin{array}{r}927.00 \\
443.64 \\
10788.50 \\
474.83 \\
307.57\end{array}$ & $\begin{array}{l}2.09 \\
35.08^{* *} \\
1.54\end{array}$ \\
\hline $\begin{array}{l}\text { Speech-sound } \\
\text { Age (A) } \\
\text { Subjects within ages (S) } \\
\text { Oddity position (O) } \\
\text { A x O } \\
\text { S x O }\end{array}$ & $\begin{array}{r}6 \\
28 \\
2 \\
12 \\
56\end{array}$ & $\begin{array}{r}154.50 \\
50.95 \\
560.95 \\
34.48 \\
49.10\end{array}$ & $\begin{array}{c}3.03 * \\
11.42 * *\end{array}$ \\
\hline $\begin{array}{l}\text { Successive tone } \\
\text { Age (A) } \\
\text { Subjects within ages (S) } \\
\text { Oddity position (O) } \\
\text { A x O } \\
\text { S x O }\end{array}$ & $\begin{array}{r}6 \\
28 \\
2 \\
12 \\
56\end{array}$ & $\begin{array}{r}837.66 \\
650.86 \\
12457.70 \\
310.10 \\
384.26\end{array}$ & $\begin{array}{c}1.29 \\
34.42 * *\end{array}$ \\
\hline
\end{tabular}


Table 3

Percentages of Response to Odd Stimuli for 35 Nomal Children, with Correct Responses in Italics.
Table 5

Percentages of Response to Odd Stimuli for 15 Children with Learning Problems, with Correct Responses in Italics.

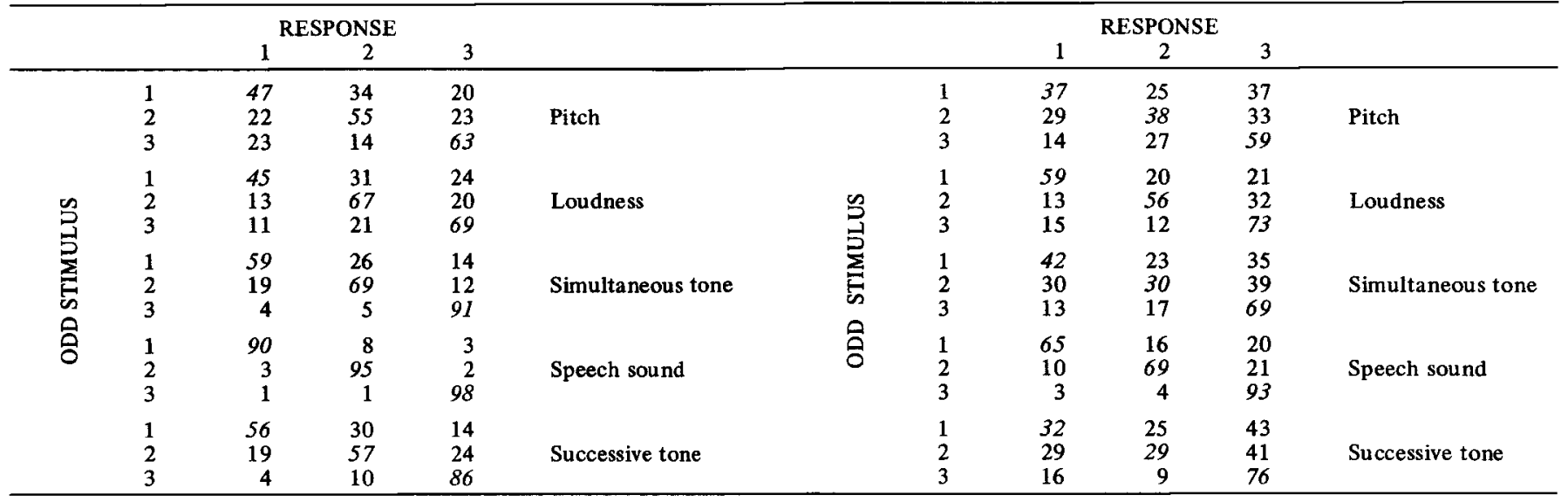

odd, there was no consistent difference in responses to the first and second positions.

\section{DISCUSSION}

The present study was concerned with oddity discrimination rather than oddity learning, since $S s$ were required to demonstrate an understanding of the oddity principle on the pretraining trials. Accuracy of discrimination of both simple and complex auditory stimuli was significantly affected by the temporal position of the odd stimulus for both groups of children. Although the two groups differed with respect to the relative difficulty of second-position oddity, it can be concluded that third-position oddity was easier to discriminate than first-position oddity.

The normal children exhibited no systematic confusion or response bias in their incorrect responses, other than a tendency for more incorrect responses to the second than to the third sound when the first sound was odd. The children with learning problems, however, seemed to have a consistent bias to respond to the third sound in their incorrect responses to first- and second-position oddity. This could have contributed to their greater accuracy in responding to third-position oddity.

\section{Table 4}

Summary of Analyses of Variance of Correct Responses to the Three Odd Stimuli for 15 Children with Learning Problems, Ages 8 to 10 .

\begin{tabular}{lrrr}
\multicolumn{1}{c}{ Source } & df & MS & F \\
\hline Pitch & & & \\
Subjects (S) & 14 & 724.19 & $6.73^{* *}$ \\
Oddity position (O) & 2 & 3697.30 & \\
S X O & 28 & 549.01 & \\
Loudness & & & 3.31 \\
Subjects (S) & 14 & 456.90 & \\
Oddity position (O) & 2 & 1732.20 & \\
S x O & 28 & 522.34 & $8.72 * *$ \\
Simultaneous tone & & & \\
Subjects (S) & 14 & 141.46 & \\
Oddity position (O) & 2 & 5192.01 & \\
S x O & 28 & 595.30 & \\
Speech sound & & & \\
Subjects (S) & 14 & 372.33 & \\
Oddity position (O) & 2 & 3441.70 & \\
S x O & 28 & 216.59 & \\
Successive tone & & & \\
Subjects (S) & 14 & 290.54 & \\
Oddity position (O) & 28 & 7853.75 & \\
S x O & & 941.98 & \\
\hline
\end{tabular}

** $p<.01$
There are several possible explanations for the observed patterns of oddity responding. The most accurate responses to third-position oddity can be explained by assuming that a Same-Different judgment of the first and second stimuli may be followed by a Same-Different judgment of the second and third stimuli. A Same judgment of the first and second stimuli leads directly to a choice of the third stimulus as odd, with no judgment of the second and third stimuli required. A Different judgment of the first and second stimuli can be followed by either a Same or a Different judgment of the second and third stimuli. The successive judgments Different-Same lead to a choice of the first stimulus as odd; Different-Different judgments lead to a choice of the second stimulus as odd. Thus, a correct response to third-position oddity requires only one correct judgment, whereas a correct response to first- or second-position oddity requires two correct judgments.

Some of the other findings can also be explained by this simple model, but less well. The poorer discrimination ability of the children with learning problems could lead to a higher proportion of Same judgments of the first and second sounds, and thus produce an apparent response bias for the third position. The intermediate accuracy of normal children for second-position oddity is difficult to explain in terms of the successive judgment model. A discrimination of difference might conceivably be easier than a discrimination of sameness after an initial Different judgment; or an initial Different judgment might create a set to emit a second Different judgment. However, such an explanation would not be applicable to the results for the children with learning problems, who did not show intermediate accuracy for second-position oddity.

The successive-judgment model provides a straightforward explanation of the easier discrimination of third-position oddity, but becomes rather tenuous when applied to other aspects of the data. Oddity responding might also be considered in terms of somewhat higher-level processes. The $\mathrm{S}$ may base his oddity discrimination upon some sort of trace or Gestalt of a single temporal pattern, and try to detect variation in the beginning, middle, or end of the pattern; or he may scan a recurring sequence of neural aftereffects in the manner proposed by Lashley (1951) rather than make a unidirectional series of judgments. In the latter case, tentative Same-Different judgments might be made during stimulus presentation, and modified by repeated scanning in doubtful cases.

A more explicit explanation of temporal sequence effects will await further analysis of auditory oddity responding. Such analyses may shed further light on the role of perceptual memory 
(cf. Kinchla \& Smyzer, 1967) in auditory discrimination. The possible importance of sequence learning for the acquisition of verbal skills has been suggested by a number of investigators (cf. Doehring, 1968; Efron, 1963; Furth, 1964; Kinsbourne \& Warrington, 1963).

Further analysis of sequential effects in auditory oddity responding can take a number of directions:

(1) A different pattern of response may occur for verbal stimuli because of the ease of rehearsal, although it should be noted that both groups in the present study exhibited the characteristic pattern of response to speech sounds.

(2) Increasing the number of identical sounds would add to the number and complexity of successive judgments, thus placing more burden on perceptual memory.

(3) The role of perceptual memory can also be assessed by varying the interval between sounds.

(4) Oddity discrimination can be compared with other auditory discrimination methods such as the single SameDifferent judgment, matching to sample, and the ABX method. Such comparisons should reveal the relative efficiency of the various procedures for defining the limits of auditory discrimination and should permit a comparative analysis of sequence effects.

(5) Comparison of visual and auditory oddity responding, using both simultaneous and successive visual stimuli, should provide a further understanding of the differences between these two modalities.

(6) Changes in patterns of auditory oddity responding as a function of stimulus similarity should be systematically investigated.

(7) Finally, a return to the basic concern of the original investigators of visual oddity might prove fruitful. Studies of auditory oddity learning in both humans and animals in situations where no pretraining is given should tell us something about the manner in which strategies of responding to temporal sequences are developed.

\section{REFERENCES}

BITTERMAN, M. E., \& WODINSKY, J. The solution of oddity and non-oddity problems by the rat. American Psychologist, 1953, 8, 458.

BOYD, B. O., \& WARREN, J. M. Solution of oddity problems by cats. Journal of Comparative \& Phy siological Psychology, 1957, 50, 258-260.

CANDI AND, D. K., \& CONKLYN, D. H. Use of the "oddity problem" in teaching mentally retarded deaf-mutes to read: A pilot project. Training School Bulletin, 1962, 59, 38-41.

DOEHRING, D. G. Patterns of impairment in specific reading disability. Bloomington, Ind.: Indiana University Press, 1968.

EFRON, R. Temporal perception, aphasia, and deja vu. Brain, 1963, 86, 403-424.

ELLIS, N. R., \& SLOAN, W. Oddity learning as a function of mental age. Journal of Comparative \& Physiological Psychology, 1959, 52, 228-230.

FURTH, H. G. Sequence learning in aphasic and deaf children. Joumal of Speech \& Hearing Disorders, 1964, 29, 171-177.
GOLlin, E. S., SARAVO, A., \& SALTIN, C. Perceptual distinctiveness and oddity-problem solving in children. Journal of Experimental Child Psychology, 1967, 5, 586-596.

GOLLIN, E. S., \& SHIRK, E. J. A developmental study of oddity-problem learning in young children. Child Development, 1966, 37, 213-217.

HILL, S. D. The performance of young children on three discriminationlearning tasks. Child Development, 1965, 36, 425-435.

HOUSE, B. J. Oddity performance in retardates: I. Acquisition and transfer. Child Development, 1964a, 35, 635-643.

HOUSE, B. J. Oddity performance in retardates: II. Size discrimination functions from oddity and verbal methods. Child Development, 1964b, 35, 645-651.

KINCHLA, R. A., \& SMYZER, F. A diffusion model of perceptual memory. Perception \& Psychophysics, 1967, 2, 219-229.

KINSBOURNE, M., \& WARRINGTON, E. K. Developmental factors in reading and writing backwardness. British Journal of Psychology, 1963, $54,145-156$.

LASHLEY, $K$. S. The problem of serial order in behavior. In L. A. Jeffress (Ed.), Cerebral mechanisms in behavior. New York: John Wiley, 1951.

LIPSETT, L. P., \& LoLORDO, V. M. The interactive effect of stress and stimulus generalization on children's oddity learning. Journal of Experimental Psychology, 1963, 66, 210-214.

LIPSETT, L. P., \& SERUNIAN, S. A. Oddity-problem learning in young children. Child Development, 1963, 34, 201-206.

LUBKER, B. J., \& SPIKER, C. C. The effects of irrelevant stimulus dimensions on children's oddity-problem learning. Journal of Experimental Child Psychology, 1966, 3, 207-215.

MOON, L. E., \& HARLOW, H. F. Analysis of oddity learning by rhesus monkeys. Journal of Comparative \& Physiological Psychology, 1955, 48, 188-194.

PICKETT, J. M., \& MÁRTONY, J. Low-frequency single formant discrimination in deaf listeners. Paper presented at the meeting of the Acoustical Society of America, Ottawa, May, 1968.

SEASHORE, C. E., LEWIS, D., \& SAETVEIT, J. G. Seashore measures of musical talent (Rev. ed.). New York: The Psychological Corporation, 1960.

STRONG, P. N. Comparative studies in simple oddity learning. II. Children, adults, and seniles. Psychonomic Science, 1966, 6, 459-460.

STRONG, P. N., \& HEDGES, M. Comparative studies in simple oddity learning. I. Cats, raccoons, monkeys, and chimpanzees. Psychonomic Science, 1966, 5, 13-14.

TEMPLIN, M. Certain language skills in children. Minneapolis: University of Minnesota Press, 1957.

\section{NOTES}

1. This research was supported by Grants MA-1652 from the Medical Research Council of Canada and 604-7-507 from the Canadian Department of National Health and Welfare.

2. The writer wishes to thank Dr. M. S. Rabinovitch for his help in planning and carrying out this research; Mr. Robert Leicester, Principal of St. George's School, Montreal, for his cooperation in the testing of normal children; and Miss Andree Durieux and Miss Eliane Shilton for the administration of tests.

3. Address: McIntyre Medical Sciences Bldg., McGill University, Montreal 2, Canada.

4. Doehring, D. G., and Rabinovitch, M. S. Auditory abilities of children with learning problems. Unpublished manuscript.

(Accepted for publication January 20, 1969.) 